\title{
Efficiency and Productivity Changes of Commercial Banks and the Branches in China During 2007-2019 A DEA-Malmquist Approach
}

\author{
Libo Li, Wenbing $\mathrm{Wu}^{*}$ and Mingyu Zhang
}

\author{
School of Economics and Management, Beijing Jiaotong University, P.R. China, 100044 \\ *Corresponding author. Email: wbwu@bjtu.edu.cn
}

\begin{abstract}
Efficiency and productivity changes in the banking sector are important because understanding whether financial resource allocation is efficient provides the basis of policymaking, routine management, and bank reforms. Using a DEA-Malmquist approach, this study firstly compared bank efficiency of the major commercial banks and examined whether their productivity has improved. The study then took Agricultural Bank of China (ABC) as an example to investigate efficiency and productivity changes of its branches. Results indicated that the annual average technical efficiency of stock-holding banks was lower than those of city commercial banks and state-owned banks. The shortage of state-owned banks was scale efficiency. Reducing size scales of input resources (i.e., staff, total assets, loans and payments) can be an effective way to improve state-owned banks' efficiency. Regarding the ABC's branches, those in Bohai Rim region, Central region and Northeast region had shortages in pure technical efficiency; while those in Yangtze Delta region, Pearl Delta region and West region should focus on improving scale efficiency. The findings of this study may assist managers, policymakers, and regulators of banks in China in evaluating banks' competitiveness.
\end{abstract}

Keywords: Bank efficiency, Productivity change, DEA-Malmquist approach.

\section{INTRODUCTION}

In recent years, China's banking industry has experienced many reforms, such as financial deregulation, transforming the shareholding system, digitalizing business, being listed on stock market and so on. Those reforms are attempts to improve the efficiency of the country's financial system [1]. In recent years, there has been an increasing amount of literature on evaluating bank efficiency in China. The study by Chen et al. [2] is the early attempt to evaluate Chinese bank efficiency. The authors examined the cost, technical and allocative efficiency of 43 Chinese banks from 1993 to 2000 to investigate the impact of financial deregulation in 1995 on bank efficiency. In the Chinese bank efficiency research, other scholars focus on its changing trend [3, 4], financial crisis's impact [5], risk management [6], etc. However, few research studies have investigated the performance of commercial bank's branches due to lack of public data on bank branches. Since data envelopment analysis (DEA) and Malmquist productivity index are widely applied together to measure bank efficiency and its changes, this paper used the DEA- Malmquist approach to evaluate efficiency of major commercial banks in China. We further extended the approach to the branches in $\mathrm{ABC}$ to study performance variations among branches in the same bank.

The rest of this paper is organized as follows. Section 2 introduces the method and data used. Section 3 presents the major results on the efficiency and productivity changes of the branches. Section 4 is concluding remarks.

\section{METHODOLOGY}

\subsection{Data Envelopment Analysis (DEA)}

Data Envelopment Analysis (DEA) is a quantitative method frequently used to assess the efficiency of multiple input and output variables. DEA is a nonparametric method for evaluating the relative efficiency among decision-making units (DMU). The nonparametric method does not need to determine 
production function or cost function in advance. Meanwhile, it can be used to evaluate indicators with different dimensions. It also has advantages of low requirements on sample size and strong objectivity. DEA has been adopted to analyze bank efficiency in recent years $[1,7,8]$ since the first application in bank sector in 1985 [9].

The basic principle of DEA is as follows. First, the production frontier is determined by using linear programming and multi-objective programming methods, that is, the curve composed of DMU with the best efficiency (i.e., relative efficiency equals one). Second, the output and input variables of other DMUs whose relative efficiencies are less than one are projected to the production frontier. The distance between the DMUs and the production frontier is calculated, that is, the deviation degree. The higher the deviation degree, the lower the relative efficiency. A DMU with a relative efficiency of one is called DEA efficient; otherwise, a DMU is called DEA inefficient. Therefore, to judge whether a DMU is DEA efficient is essentially to judge whether the DMU is on the production frontier.

There are two basic models in DEA, CCR model and BCC model. In CCR model, an assumption is constant returns to scale; while in BCC model, variable returns to scale are assumed. Technical efficiency in CCR (TE) equals to pure technical efficiency in BCC (PTE) multiplied by scale efficiency (SE). In this study, TE means efficiency of allocation, utilization and scale aggregation of financial resources such as staff, loans and assets. PTE means the efficiency of financial resources caused by technological innovation. The higher PTE value, the higher efficiency of resource allocation and utilization caused by technologies. SE refers to scale aggregation efficiency of financial resources.

\subsection{Malmquist Productivity Index}

When dealing with panel data in DEA, there are different production frontiers in different years. DMUs in different years lack of comparableness. The DEA method can only deal with cross-section data. Therefore, Malmquist productivity index is usually used to combine with DEA method to analyze DMUs' efficiencies in various years. Malmquist productivity index is a metric to evaluate changes of total factor production (TFP), which was widely used with DEA method together in efficiency assessment since 1994 [10].

The basic equations of the DEA and Malmquist productivity index can be found in the literature [9-12], which are not listed due to space limitation.

\subsection{Variables and Data}

\subsubsection{Variables Selection}

The variable selection is a crucial step in DEA which can considerably affect the results of DEA [8]. Many researchers have made much effort in selecting input and output variables in DEA on bank efficiency. There are three major methods in this field according to the considerations on different roles of banks: producerbased, intermediate, and asset-based methods [4]. The three methods have their own advantages and disadvantages, and they are all feasible methods. The method adopted depends on the purpose of research work and data availability. In this study, we chose staff numbers, total assets and loans and payments as input variables, and net profit and operating revenue as output variables.

\subsubsection{Sample Data}

There are two parts to the empirical study. In peer comparison, the 17 listed commercial banks were selected. They are classified into three types: four stateowned banks (ICBC, ABC, BOC, CCB), nine stockholding banks (BoCom, CMBC, SPDB, CITIC, CEB, $\mathrm{HXB}, \mathrm{CMBC}, \mathrm{CIB}, \mathrm{PAB})$, and four city commercial banks (BJB, NBB, NJB, HZB). The study period is 2007-2019. The data sources are annual reports of banks. There are 1105 sample data consisted of 17 sample banks, 13 years and five variables. The data description is shown in Table 1.

The 36 branches were included in the DEA on the branches of ABC. The study period is 2010-2019. The data sources are the data management system of ABC. There are 1750 sample data consisted of 36 branches, ten years and five variables. 
Table 1. Data description of commercial banks

\begin{tabular}{|c|c|c|c|c|c|c|}
\hline Category & Variables & Minimum & Maximum & Average & Median & $\begin{array}{l}\text { Standard } \\
\text { Deviation }\end{array}$ \\
\hline \multirow{3}{*}{$\begin{array}{l}\text { Input } \\
\text { Variables }\end{array}$} & Staff number & $\begin{array}{l}1629 \\
\text { NJB } \\
\text { (Year of 2007) }\end{array}$ & $\begin{array}{l}503082 \\
\text { ABC } \\
\text { (Year of 2015) }\end{array}$ & 114687.6 & 40340.0 & 154041.6 \\
\hline & $\begin{array}{l}\text { Total assets } \\
\text { [billion Yuan] }\end{array}$ & $\begin{array}{l}69.27 \\
\text { HZB } \\
\text { (Year of 2007) }\end{array}$ & $\begin{array}{l}30109.44 \\
\text { ICBC } \\
\text { (Year of 2019) }\end{array}$ & 5774.68 & 3020.79 & 6672.95 \\
\hline & $\begin{array}{l}\text { Loans and } \\
\text { payments } \\
\text { [billion Yuan] }\end{array}$ & $\begin{array}{l}29.82 \\
\text { NJB } \\
\text { (Year of 2007) }\end{array}$ & $\begin{array}{l}16326.55 \\
\text { ICBC } \\
\text { (Year of 2019) }\end{array}$ & 2939.84 & 1475.42 & 3561.60 \\
\hline \multirow{2}{*}{$\begin{array}{l}\text { Output } \\
\text { Variables }\end{array}$} & $\begin{array}{l}\text { Net Profit } \\
\text { [billion Yuan] }\end{array}$ & $\begin{array}{l}0.61 \\
\text { PAB } \\
\text { (Year of 2008) }\end{array}$ & $\begin{array}{l}313.36 \\
\text { ICBC } \\
\text { (Year of 2019) }\end{array}$ & 60.18 & 28.93 & 74.69 \\
\hline & $\begin{array}{l}\text { Operating } \\
\text { revenue } \\
\text { [billion Yuan] }\end{array}$ & $\begin{array}{l}1.93 \\
\text { NJB } \\
\text { (Year of 2007) }\end{array}$ & $\begin{array}{l}855.16 \\
\text { ICBC } \\
\text { (Year of 2019) }\end{array}$ & 164.72 & 89.44 & 191.36 \\
\hline
\end{tabular}

\section{RESULTS ANALYSIS}

\subsection{DEA Efficiency and Productivity Changes of Commercial Banks in China}

\subsubsection{DEA Efficiency}

The annual average TE value of the 17 commercial banks was 0.924 , referring to an average $7.6 \%$ waste of input resources. In particular, the annual average TE values of the four state-owned banks, the nine stockholding banks, and the four city commercial banks were $0.936,0.906$ and 0.961 , respectively. NJB was DEA efficient $(\mathrm{TE}=1.0)$, followed by $\mathrm{BJB}(\mathrm{TE}=0.998)$ and CMBC (TE=0.990).

Pure technical efficiency (PTE) indicates the operating management level. In the study period, the annual average PTE value of the 17 banks was 0.951 and those of the four state-owned banks, the nine stockholding banks and the four city commercial banks were 0.976, 0.930 and 0.998, respectively. ICBC and CCB had PTE values of 1.0. The failure of the two banks to achieve DEA efficient was due to inefficient scale efficiency.

\subsubsection{Productivity Changes}

The annual average TFP of the 17 banks was 1.004, indicating an annual average increase of $4 \%$. Figure 1 showed that due to the global financial crisis in 20082009 , it dropped to the lowest level in the study period (0.808), and then increased rapidly to the highest level in the study period (1.134) in 2009-2010 and 20102011. After that, the TFP showed a downward trend in 2014-2015 and 2015-2016. The TFP increased again from 2017 and reached 1.029 in 2018-2019.

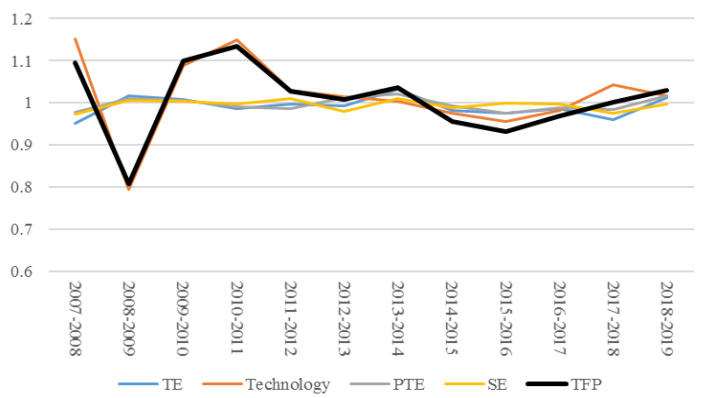

Figure 1 Changing trend in Malmquist productivity indices and the compositions

\subsubsection{DEA Efficiency and Productivity Changes of $A B C$}

The annual average TE value of $\mathrm{ABC}$ was 0.910 , which ranked 12th among 17 banks and the third among four state-owned banks. During the study period, $9.0 \%$ of the input resources were wasted. The efficiency of ABC reached DEA efficient only in 2007 and 2010 and showed a downward trend in recent years. In 2019, the TE value reached the lowest value in the study period (0.759), indicating that compared with other banks, the input-output efficiency level of $\mathrm{ABC}$ was lower, and the promotion and improvement momentum was slower than that of other banks.

The annual average PTE value of ABC was 0.984 , ranking the second among state-owned banks and the sixth among 17 banks. In 2007, and from 2010 to 2015, it achieved pure technical efficiency but decreased year by year from 2016 to 2019, and 2019 was the lowest value in the study period (0.908). It shows that the routine operation and management level of $\mathrm{ABC}$ was at the upper-middle level among the 17 banks. However, in recent years, there is a problem with input-output redundancy, and the failure to achieve comprehensive technical effectiveness was mainly due to the low level 
of SE (0.925). The SE ranked the last second one. Except for 2007, 2009 and 2010, the ABC's SE value was not 1and showed an overall downward trend, reaching the lowest value (0.794) in 2018 and rebounding (0.836) in 2019. The annual average TFP of $\mathrm{ABC}$ in the study period equaled to 0.971 , ranking the last one in the 17 banks.

\subsection{DEA Efficiency and Productivity Changes of Large State-owned Commercial Bank's Branches: A Case Study in Agricultural Bank of China}

The bank efficiency of $\mathrm{ABC}$ was of low rank among the studied banks. Its TE, PTE, and SE were all DEA inefficient from 2016 and had decreasing trends. Meanwhile, the TFP of ABC ranked lowest among the 17 commercial banks. To further understand the shortcomings of ABC's bank efficiency, we analyze efficiency of its branches based DEA-Malmquist method.

\subsubsection{DEA Efficiency}

The results showed that the annual average of all 36 branches was 0.923 , indicating there was a $7.7 \%$ waste of input resources. Shenzhen branch had the highest relative TE (TE equaled one) which was DEA efficient (Figure 2).

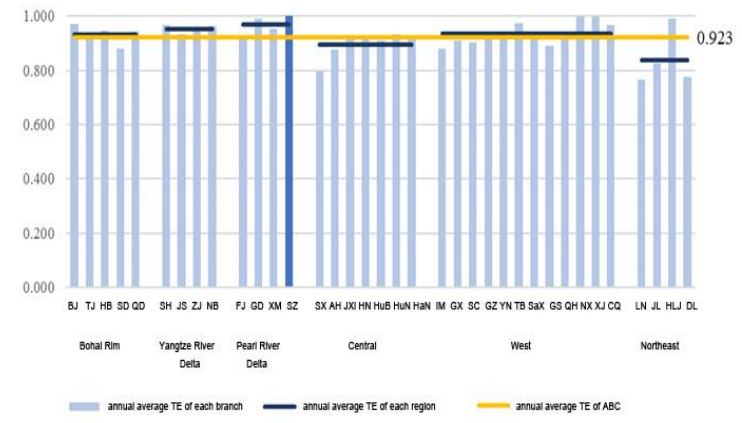

Figure 2 Annual average technical efficiency of the 36 ABC branches (2010-2019)
Note: the dark blue bar indicates that TE value of this branch equals one.

Figure 3 presents an efficiency comparison of the $\mathrm{ABC}$ branches in different regions. The average PTE values of all branches were lower than the average SE values, indicating that PTE caused the bank's inefficiency. Therefore, operating management should be improved to promote bank efficiency. Regarding different regions, Bohai Rim Region, Central Region and Northeast Region had similar features with the average; while Yangtze River Delta Region, Pearl River Delta Region and West Region should focus on improving scale efficiency.

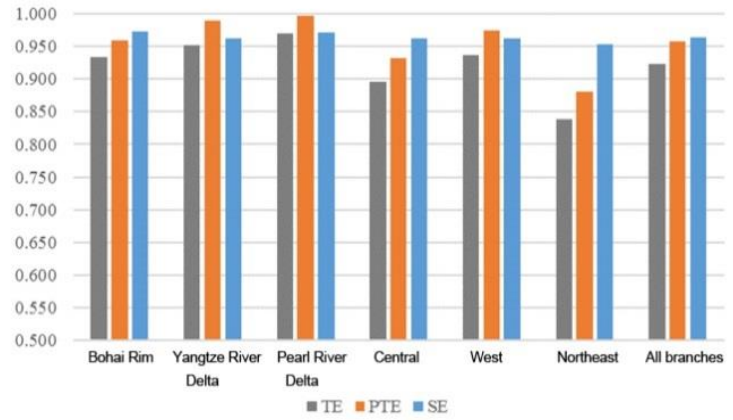

Figure 3 Average TE, PTE, and SE values of the 36 $\mathrm{ABC}$ branches in the various regions

\subsubsection{Productivity Changes}

Table 2 shows the annual average Malmquist productivity indices and their composition of the 36 ABC branches during 2010-2019. The annual average productivity of all branches decreased by $1.5 \%$, with the annual average Malmquist productivity index value of 0.985 . The values of Malmquist productivity indices before 2013 had a decreasing trend and in 2012-2013 reached the lowest value of 0.805 . After being lower than 1 for four years from 2013 to 2017, the index increased slightly to 1.016 . However, in the recent 2018-2019, the index decreased to 0.982 .

Table 2. Annual average Malmquist productivity indices of the $36 \mathrm{ABC}$ branches (2010-2019)

\begin{tabular}{|c|c|c|c|c|c|}
\hline Index & Changes in TE & $\begin{array}{c}\text { Changes in } \\
\text { Technology }\end{array}$ & Changes in PTE & Changes in SE & $\begin{array}{c}\text { Changes in } \\
\text { TFP }\end{array}$ \\
\hline $2010-2011$ & 0.999 & 1.164 & 0.997 & 1.001 & 1.162 \\
\hline $2011-2012$ & 0.983 & 1.194 & 1.009 & 0.974 & 1.173 \\
\hline $2012-2013$ & 0.979 & 1.083 & 0.991 & 0.987 & 1.060 \\
\hline $2013-2014$ & 1.027 & 0.783 & 0.995 & 1.033 & 0.805 \\
\hline $2014-2015$ & 0.969 & 0.985 & 0.984 & 0.985 & 0.955 \\
\hline $2015-2016$ & 0.977 & 0.859 & 0.996 & 0.981 & 0.84 \\
\hline $2016-2017$ & 1.027 & 0.91 & 1.019 & 1.008 & 0.935 \\
\hline $2017-2018$ & 1.013 & 1.002 & 0.99 & 1.024 & 1.016 \\
\hline $2018-2019$ & 0.99 & 0.991 & 1 & 0.99 & 0.982 \\
\hline Annual average & 0.996 & 0.989 & 0.998 & 0.998 & 0.985 \\
\hline
\end{tabular}


The decrease of TFP in ABC's branches mainly attributed to changes in technology, which had an annual average decrease of $1.1 \%$. Other compositions also contributed to the decrease of TFP, with an annual average decrease of $0.4 \%$ in TE, $0.2 \%$ in PTE and $0.2 \%$ in SE. In particular, the changing trend of changes in technology was similar to that of TFP, that is, decreasing before 2013, a slight increase to 1.002 in 2017-2018 and then decreasing to 0.991 in 2018-2019. The other three compositions were relatively steady and fluctuated around 1 .

\section{CONCLUSIONS}

This paper analyzes commercial bank efficiency and productivity changes during 2007-2019 in the Chinese banking sector. The DEA method is applied to calculate technical efficiency (TE), pure technical efficiency (PTE), and scale efficiency (SE), and the 17 listed commercial banks are taken as examples. We choose staff numbers, total assets and loans and payments as input variables and net profits and operating revenue as output variables. The Malmquist productivity index is then used to analyze productivity changes in bank total factor productivity during 2007-2019. After analyzing different commercial banks' efficiency, we use the 36 branches of Agricultural Bank of China to evaluate branches' efficiency using the DEA-Malmquist-based method. We summarize our results as follows.

First, we find that the annual average TE value equaled to 0.924 during 2007-2019, indicating there was $7.6 \%$ waste in input resources. The annual average TE values of stock-holding banks were lower than those of city commercial banks and state-owned banks. During the study period, there was a fluctuating downward trend in TE values, and the decline was obvious from 2014. The average TE value of Nanjing Bank is the highest (1.0), which means the technical efficiency of each year was DEA effective. The efficiency of China Construction Bank was the best (the annual average TE value equaled 0.979) in all the state-owned banks.

Second, the calculations show the annual average PTE value equaled to 0.951 , with the value lower than that of SE (0.972). This result indicates to improve bank efficiency mainly relies on routine operating management instead of expanding the operating scale. The stock-holding banks had a lower PTE value but a higher SE value than other two kinds of banks. The shortage of state-owned banks was scale efficiency. The scale return of the state-owned banks has declined in the study period. Reducing size scales of input resources (i.e., staff, total assets, loans and payments) can be an effective way to improve state-owned banks' efficiency.

Third, the TE, PTE, and SE of ABC all ranked near the bottom of the commercial banks. It is necessary to update its efficiency in routine operating management, reducing size scales of input resources, and promoting technological innovation. Regarding its branches, the branches in Bohai Rim region, Central region and Northeast region had shortages in PTE; while the branches in Yangtze Delta region, Pearl Delta region and West region should focus on improving SE.

Abbreviations of the banks: ICBC (Industrial and Commercial Bank of China), ABC (Agricultural Bank of China), BOC (Bank of China), CCB (China Construction Bank), BoCom (Bank of Communications), CMBC (China Merchants Bank), SPDB (Shanghai Pudong Development Bank), CITIC (China CITIC Bank), CEB (China Everbright Bank), HBX (Hua Xia Bank), CMBC (China Minsheng Bank), CIB (China Industrial Bank), PAB (Ping An Bank), BJB (Beijing Bank), NBB (Ningbo Bank), NJB (Nanjing Bank), HZB (Hangzhou Bank).

\section{AUTHORS' CONTRIBUTIONS}

Libo Li analysed the data and writing the first draft. Wenbing $\mathrm{Wu}$ reviewed the draft and revised it. Mingyu Zhang reviewed the draft.

\section{ACKNOWLEDGMENTS}

This research was financially supported by the Science and Technology Foundation of Beijing Jiaotong University (2018JBWZB003).

\section{REFERENCES}

[1] Li Y. Analyzing efficiencies of city commercial banks in China: An application of the bootstrapped DEA approach. Pacific-Basin Finance Journal. 2020; 62:101372.

[2] Chen X, et al. Banking efficiency in China: Application of DEA to pre- and post-deregulation eras: 1993-2000. China Economic Review. 2005; $16: 245$.

[3] Yao S and Jiang C. Banking Reform and Efficiency in China: 1995-2008. Economic Research Journal. 2011.

[4] Zhang J. Efficiency evaluation of commercial banks in China and empirical analysis from 1997 to 2001: a DEA method. Journal of Financial Research. 2003:11-25(in Chinese).

[5] Chen Z, et al. Chinese bank efficiency during the global financial crisis: A combined approach using satisficing DEA and Support Vector Machines. The North American Journal of Economics and Finance. 2018; 43:71-86. 
[6] Matthews K. Risk Management and Managerial Efficiency in Chinese Banks: A Network DEA Framework. Omega. 2013; 41:207-215.

[7] Liu M, et al. Calculation and analysis of the contribution rate of technological progress in China's oil \& gas exploration and development industry based on the DEA method. Petroleum Science Bulletin. 2020; 5:290-298(in Chinese).

[8] Yan L, et al. Input/output indicator selection for DEA efficiency evaluation: An empirical study of Chinese commercial banks. Expert Systems with Applications. 2012; 39:1118-1123.

[9] Sherman HD and Gold F. Bank branch operating efficiency: Evaluation with data envelopment analysis. Journal of banking \& finance. 1985; 9:297-315.

[10] Färe R, et al. Productivity growth, technical progress, and efficiency change in industrialized countries. The American economic review. 1994:66-83.

[11] Banker RD, et al. Some models for estimating technical and scale inefficiencies in data envelopment analysis. Management Science. 1984; 30:1078-1092.

[12] Charnes A, et al. Measuring the efficiency of decision making units. European journal of operational research. 1978; 2:429-444. 